\title{
Research into phase transformations in reservoir systems models in the presence of thermodynamic hydrate formation inhibitors of high concentration
}

\author{
Nazar Pedchenko ${ }^{1}$, Ivan Zezekalo ${ }^{1}$, Larysa Pedchenko ${ }^{1}$, and Mykhailo Pedchenko ${ }^{1 *}$ \\ ${ }^{1}$ National University "Yuri Kondratyuk Poltava Polytechnic", Oil and Gas Engineering and \\ Technology Department, 24 Pershotravnevyi Ave., 36011, Poltava, Ukraine
}

\begin{abstract}
Gas hydrates have been and still remain a difficult problem in the oil and gas industry, solution of which requires considerable efforts and resources. In this work, the mechanism of phase transformations at negative temperatures in the formation of the solid phase is preliminarily studied using the reservoir system models consisting of a gas mixture and a solution of gas hydrate formation inhibitor of thermodynamic action with high concentration in distilled water. A system of three-dimensional lighting and image magnification is used to visually detect phase boundaries by creating optical effects. Thus, in the system "inhibitor solution - gas hydrate - gas" in the process of gas hydrate recrystallization in the conditions close to equilibrium, microzones of supercooled water may occur, which in the absence of gas molecules access is crystallized into ice. The result of such solid phase structure formation is its increased stability in nonequilibrium conditions for a relatively long period of time.
\end{abstract}

\section{Introduction}

Gas hydrates are currently considered as an alternative source of natural gas in the near future [1-4]. Also, the property of gas hydrates to bind large gas volumes in relatively mild conditions allows to consider them as an alternative to traditional technologies of natural gas transportation and storage [5-9]. In addition, a number of technologies have been developed where gas hydrates act as target or intermediate products [5, 9-14]. However, gas hydrates have been and still remain a difficult problem in the oil and gas industry, solution of which requires considerable efforts and resources $[15,16]$. In this regard, an important task is to thoroughly study the gas hydrates properties, ways to prevent the hydrates formation, as well as the processes occurring in reservoir systems under conditions of hydrate formation [17-19]. Information obtained from experimental research is the most reliable and valuable.

Common methods for determining equilibrium parameters of hydrate formation provide for a sufficiently long system exposure after changing the parameter for its transition to

*Corresponding author: pedchenkomm@ukr.net 
equilibrium. Of course, the data obtained from such research are the most accurate. They, for example, make it possible to qualitatively assess the inhibitors effectiveness of the process or to determine the equilibrium parameters of gas hydrate formation with a certain composition.

However, from the viewpoint of the problem of preventing gas hydrate formation in the process of oil and gas production, this approach is often not sufficient when assessing the reservoir systems characteristics. The dynamics of processes in the system where the gas hydrate is formed (or ice, and therefore the solid phase) is important information in real conditions. Moreover, information about the behavior of the system within the time of its stay in the critical zone of the technological unit or pipeline may be the most important. In this case, the system may be in nonequilibrium conditions.

At the same time, for production processes the very fact of the presence in technological equipment of solid phase inclusions in the fluid flow composition is not critical. The main thing is that the solid phase does not cause complications (plugs). Today, guided by this principle, anti-agglomerates are developed and widely used.

From the point of view of possible hydrate formation, the most critical thermobaric conditions are observed in the winter period and in technological lines of low-temperature processes. A concentrated hydrate formation inhibitor is added to the gas stream to prevent hydrate formation. In these processes, the water-saturated inhibitor is a condensed phase. Methanol is mostly used as an inhibitor in Ukrainian deposits. Its concentration in a saturated water-methanol mixture is not less than $40-50 \%$.

At the same time, gas hydrate is formed from water and gas molecules with a certain supercooling of the system, even at this concentration of inhibitor. The danger of plugging the production line arises as a result.

In addition, when using thermodynamic inhibitors, it is believed that the introduction of the calculated inhibitor rate, increased by a certain percentage in case of deviations in the technological process, can guarantee the prevention of hydrate formation. Additional negative impact on the environment and increase in production costs is a consequence of this approach.

Thus, information about the peculiarities of the hydrate formation process in solutions of highly concentrated inhibitors can be extremely valuable. However, today there is insufficient information on laboratory studies of the hydrate formation parameters of complex gas mixtures and highly concentrated solutions of thermodynamic inhibitors (above 40-50\%). Nevertheless, the problems associated with the hydrates formation on industrial objects are periodically fixed.

Therefore, in the conditions of real technological processes, information about the state and behavior of reservoir system in the most critical conditions, including when it is out of equilibrium, is important. In this work, the mechanism of phase transformations at negative temperatures in the formation of the solid phase is preliminarily studied using the reservoir system models consisting of a gas mixture and a solution of gas hydrate formation inhibitor of thermodynamic action (methanol and ethanol) with high concentration (methanol and ethanol) in distilled water. The main source of information in the study are visual observations of the processes dynamics in the reactor. A system of three-dimensional lighting and image magnification up to 200 times is used to visually detect phase boundaries by creating optical effects.

\section{Equipment and materials}

Research is conducted on a laboratory setup, the scheme of which is shown in Fig. 1. The setup reactor is equipped with an observation window. The reactor is hinged to the frame. This makes it possible to adjust its position, and hence the position of the "liquid - gas" boundary on the plane of the observation window. 
(a)

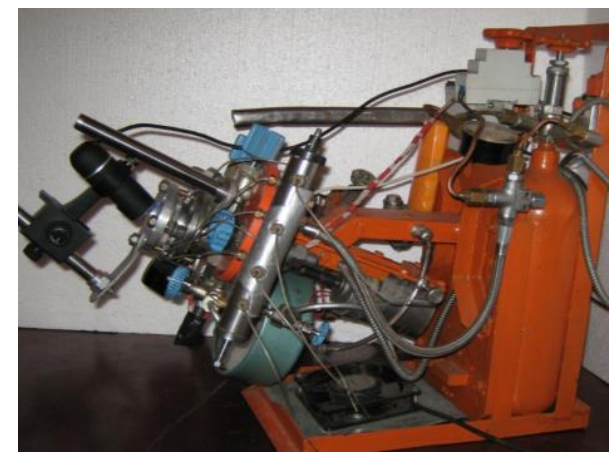

(b)

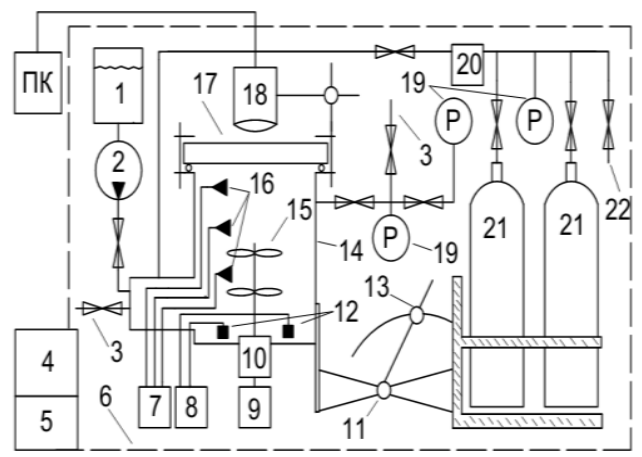

Fig. 1. Laboratory setup: (a) photo; (b) scheme: 1 - capacity; 2 - the plunger pump; 3 - liquid sampling valve; 4 - refrigeration unit; 5 - thermostat; 6 - thermal chamber; 7 - temperature control unit; 8 - power supply and LEDs control unit; 9 - electric motor; 10 - seal of the stirrer shaft; 11 - reactor hinged connection; 12 - LEDs; 13 - unit for adjusting the angle of the reactor inclination; 14 - mini reactor; 15 - the mixer; 16 - temperature control sensors; 17 - window; 18 - optical system of control and fixing the process; 19 - manometer; 20 - reducer; 21 - gas tank; 22 - gas sampling valve.

The reactor hinged connection also allows the reactor to make oscillatory movement and thus mix its contents. For more intensive stirring, the reactor is equipped with a stirrer. The reactor has a system of LEDs of different colors. It is possible to turn on and adjust the intensity of each light source separately. Similar lighting is also provided outside the reactor (around the perimeter of the observation window). This system allows to adjust the lighting parameters in the volume of the reactor for effective interphase boundary "manifestation". The volume of the reactor is $150 \mathrm{ml}$. The optimal volume of the liquid phase in the study is $60-80 \mathrm{ml}$.

The reactor unit of a setup is installed in a thermally insulated chamber. The heat exchanger of the refrigerator is located in its lower part. The reactor is cooled by circulating air in the chamber by means of two blowers. The cooling-heating velocity per $1^{\circ} \mathrm{C}$ of the reactor content averages 4-5 minutes.

The setup is equipped with a microscope with a magnification up to 200. Previous studies have shown that such a sample image magnification is the most informative (on the one hand allows to explore processes at the microlevel, and on the other, to control a significant part of the observation window). The maximum working pressure in the rector is $7 \mathrm{MPa}$. The setup allows to cool the sample to $-35^{\circ} \mathrm{C}$.

For the study, a gas mixture of the following composition is taken: $\mathrm{CH}_{4}-91.4 \%$, $\mathrm{C}_{2} \mathrm{H}_{6}-5.2 \%, \mathrm{C}_{3} \mathrm{H}_{8}-3.3 \%, \mathrm{CO}_{2}-0.1 \%$. Samples of methanol solutions (concentration 40 , 50,60 and $70 \%$ and ethanol 50,60,70 and $80 \%$ ) are investigated. The solution is prepared in distilled water. Maximum concentrations ( $70 \%$ for methanol and $80 \%$ for ethanol) are taken based on the technical capabilities of the setup to achieve the parameters of gas hydrate formation.

\section{Research method}

The test sample with a volume of $80 \mathrm{ml}$ is injected into the reactor at a temperature of $3-5^{\circ} \mathrm{C}$, the reactor is blown through with the test gas for $1 \mathrm{~min}$ with minimal intensity. To replace the dissolved air with gas molecules, the pressure is raised to $6 \mathrm{MPa}$, the stirrer is turned on every $20 \mathrm{~min}$ for $1 \mathrm{~min}$, and after $4 \mathrm{~h}$ the gas is vented. This procedure is repeated 
three times, the fourth time the reactor is kept under pressure without stirring for 12 hours. Before the experiment, the final gas replacement (blowing through) is performed.

Before to the experiment, the reactor is deflected from the vertical (Fig. 1b) so that the "liquid - gas" boundary divided the observation window approximately in half. The pressure in the reactor is raised to the required level and the gas supply is cut off. At the beginning of cooling, the stirrer is periodically turned on for a few seconds. In this position of the reactor, the stirrer blades actively capture portions of the gas and mix with the liquid. After stopping the stirrer, a small part of the smallest bubbles due to surface tension forces is attached to the glass surface below the level of the "liquid - gas" contact or concentrated in the area of this contact. Also, liquid particles remain on the glass in the form of drops and film fragments. This procedure is repeated until several gas bubbles in the liquid and drops on the glass are formed simultaneously in the viewing area of the microscope (Fig. 2).
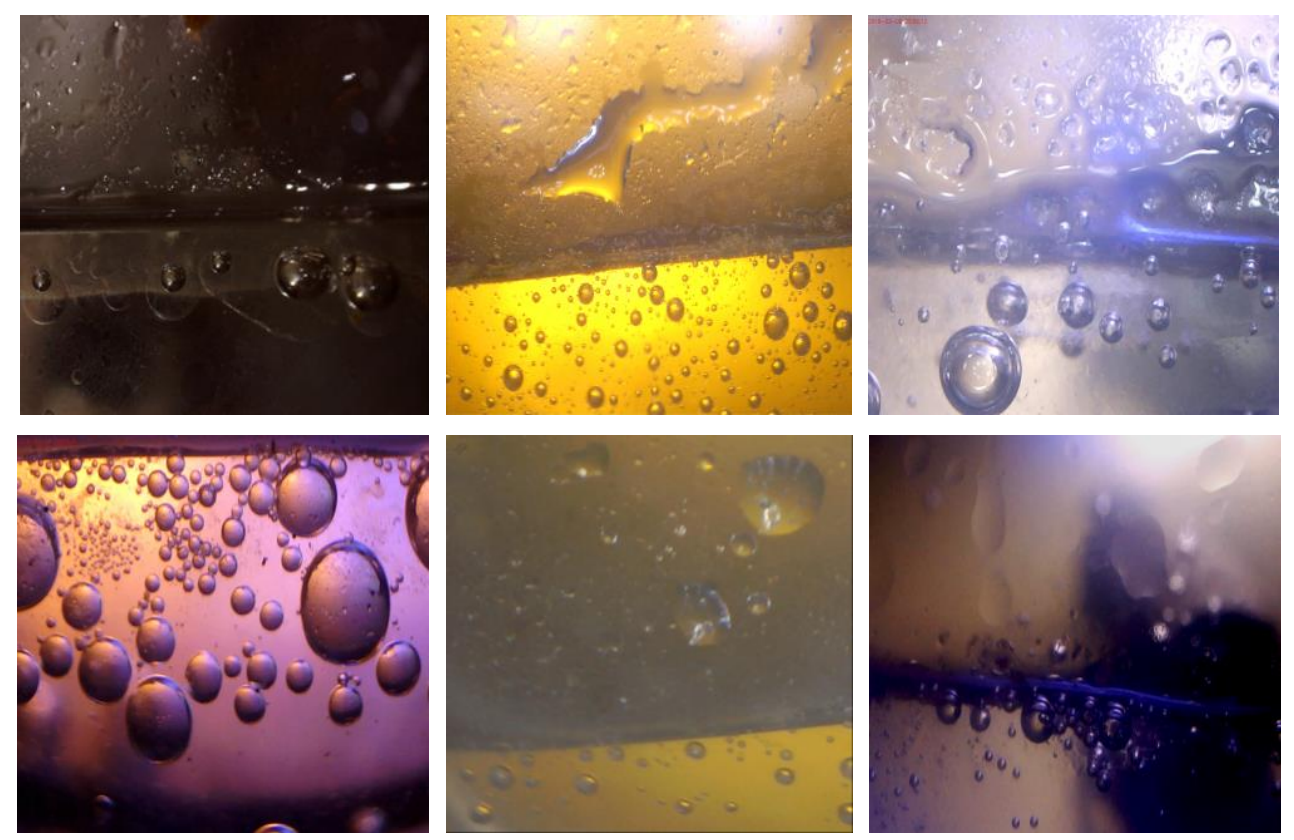

Fig. 2. Example of selecting the research object.

Then, the microscope settings are specified and the most favorable parameters of the object illumination (direction, intensity, color spectrum) are selected. For "manifestation" and high-quality fixation of the interphase boundaries, adjustments are continued during the experiment. Also, if necessary, insignificant oscillation and vibration of the reactor is periodically made (for example, to detect solid phase elements or changes in the observation object). During the experiment, the processes in the reactor are recorded on photos and video. The dynamics of temperature and pressure changes is also recorded.

During the cooling of the sample, visual signs of the solid phase formation (in the volume of liquid, on the drop surface or on the bubble surface) are recorded at some point. For each option of concentration and initial pressure, the sample cooling is continued to $-35^{\circ} \mathrm{C}$. When the minimum temperature is reached, the system is kept for 20 minutes. After that, the experiments are continued in two ways: a gradual decrease in pressure (with a velocity of $0.1-0.05 \mathrm{MPa} / \mathrm{min}$ ) or an increase in temperature (with a velocity of $0.2-0.3^{\circ} \mathrm{C} / \mathrm{min}$ ). In both cases, the velocity of parameters change does not allow the system to reach equilibrium. 


\section{Substantiation of the experimental results (mechanism of gas hydrate recrystallization to ice)}

Formation of a solid phase in the form of unconsolidated amorphous inclusions up to $1-2 \mathrm{~mm}$ in size) in a liquid is recorded during the experiment, when creating in the reactor thermobaric conditions (negative temperatures up to $-35^{\circ} \mathrm{C}$ and pressure in the range from 2 to $7 \mathrm{MPa}$ ), which exceed $\Delta T$ for the test sample (inhibitor with a concentration of 50 to $80 \%$ ) and a mixture of hydrocarbon gases (natural gas). After that, the formed solid phase is dissociated. For this, non-equilibrium conditions are created in the reactor by a relatively rapid increase in temperature (about $0.1^{\circ} \mathrm{C} / \mathrm{min}$.), but not above $0^{\circ} \mathrm{C}$, or a relatively rapid decrease in pressure to atmospheric (with a velocity of about $0.2 \mathrm{MPa} / \mathrm{min}$ ). Prolonged stability of the solid phase is recorded in the process of its dissociation. It is difficult to explain such a stability only by the manifestation of the classical effect of gas hydrate selfpreservation in the process of its dissociation [20-22].

Based on the analysis of the experimental research results, it is assumed that under the conditions described above, the solid phase formed in the system is composed of ice and hydrate mixture. In this case, the ice preserves the micro-inclusion of the gas hydrate and its mass fraction is significant.

The mechanism of ice formation process in the reservoir system in the presence of a solution of hydrate formation inhibitor of thermodynamic action with high concentration arises from the nature and properties of gas hydrates and thermodynamic action inhibitors. It can be substantiated as follows.

1. The process of gas hydrate or ice crystallization from aqueous solutions is accompanied by the displacement of the "foreign substances" molecules from the crystal lattice $[5,23]$. As a result, their concentration in the liquid phase increases. If the inhibitors of hydrate formation act as "foreign substances", an increase in their concentration in the solution leads to a shift in the equilibrium parameters towards stiffer ones compared to the initial ones for the test sample.

2. In addition, in the case of multicomponent gas mixtures, the process of hydrate formation will inevitably be accompanied by the process of gas fractionation [13]. As a result, the gas will gradually lose heavy components and be beneficiated by methane. As a result, the equilibrium parameters of hydrate formation will also be gradually changed towards stiffer ones.

3. The processes of the solid phase formation (hydrate formation), displacement of "foreign substances" from it and increase in their concentration in the liquid phase will continue until the thermobaric parameters of the system reach equilibrium. In this case, the inhibitor concentration in the liquid phase at the time of reaching equilibrium will significantly exceed the initial sample concentration. For any system, the equilibrium conditions are characterized by the velocities equality of direct and inverse processes. The result of the hydrate formation inhibitor contact with gas hydrate is its dissociation, and of water molecules with hydrate-forming gas - its formation. As experiments have shown (Fig. 3), the studied system is characterized by an active flow of both these processes. Hydrate formation and dissociation involve the release and absorption of energy. Therefore, any inhomogeneities at the phases boundary lead to a simultaneous, but scattered in space, their flow. They in turn will be a source of local microscopic energy fluctuations. In these zones, a certain deviation of temperature from equilibrium will be observed as a result of gas hydrate dissociation into supercooled water and gas, and repeated hydrate formation or its recrystallization.

4. The peculiarity of the described above process is the formation of local zones of fresh supercooled water for some time. 

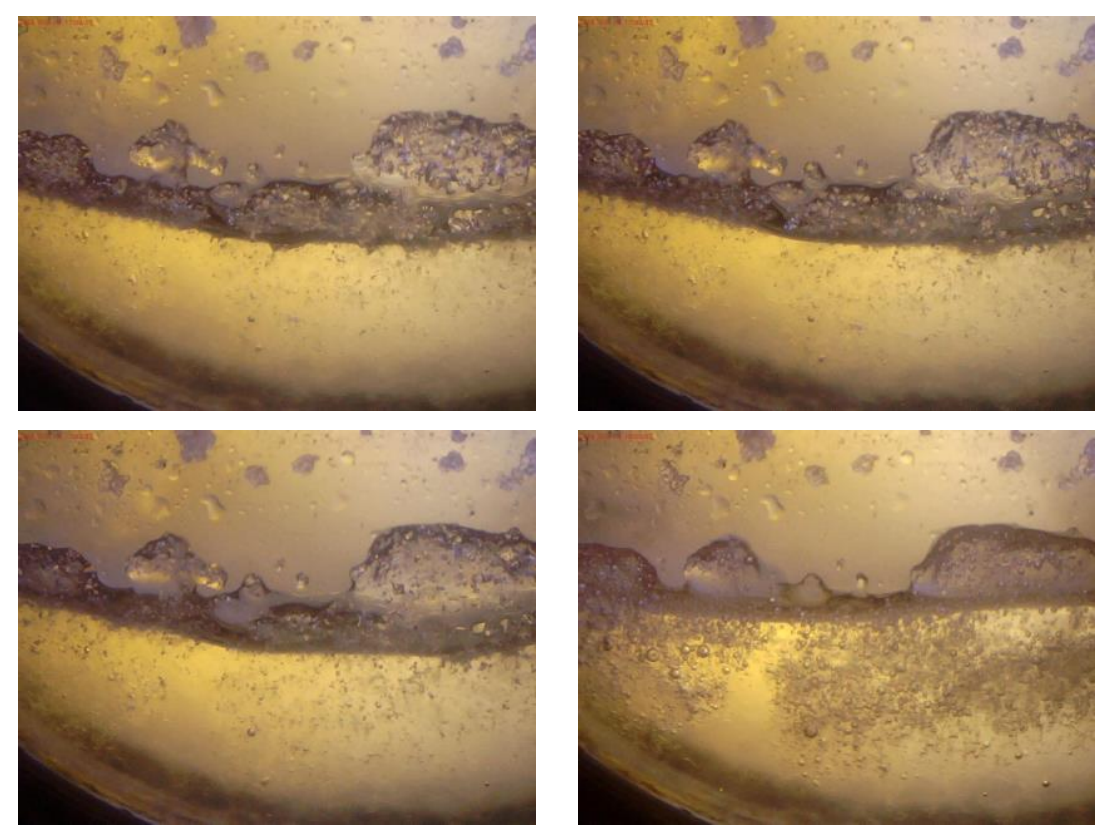

Fig. 3. An example of the recrystallization process.

5. However, in the case when there is a shortage of hydrate-forming gas molecules in this fluctuation (microvolumes) at the moment of re-crystallization of supercooled water, the dominant process will be the crystallization of water into ice. In a laboratory reactor, such conditions will be created when its content is not mixed and gas bubbles from the (liquid) migrate upwards. Thus, ice will be formed at the boundary "concentrated solution - gas hydrate".

6. In the case, when there is an access of a sufficient number of gas molecules to the microzones with supercooled water with a low concentrated inhibitor, then the repeted formation of gas hydrate will occur. In addition, it is known that water, which was previously bound into gas hydrate, has the memory of preliminary structure $[23,24]$. Therefore, the repeated formation of gas hydrate will occur more intensely in these microzones.

7. Therefore, after some time of the system kept in the conditions close to equilibrium, the surface of the hydrate particles in the inhibitor solution is recrystallized to ice. As a result, the inclusions of gas hydrate are preserved by a layer of ice. The experiments on dissociation of the formed solid phase have shown that this layer is much more stable (probably thicker) than the ice crust, which is formed as a result of the classical process of self-preservation $[20,21]$ (because the solid phase was in contact with the inhibitor!). The stability of some hydrate inclusions in the presence of a concentrated inhibitor is maintained for a long time even at temperatures up to $-3^{\circ} \mathrm{C}$ (Fig. 4). It is also likely that a similar process of gas hydrate recrystallization into ice at negative temperature continues at the stage of solid phase dissociation.

\section{Additional results that require further study}

1. Cases of occurrence in the volume of the condensed phase of localized (almost point) zones with active gas evolution (Fig. 5) are recorded in the process of visual studies of the gas hydrate dissociation mechanism. 


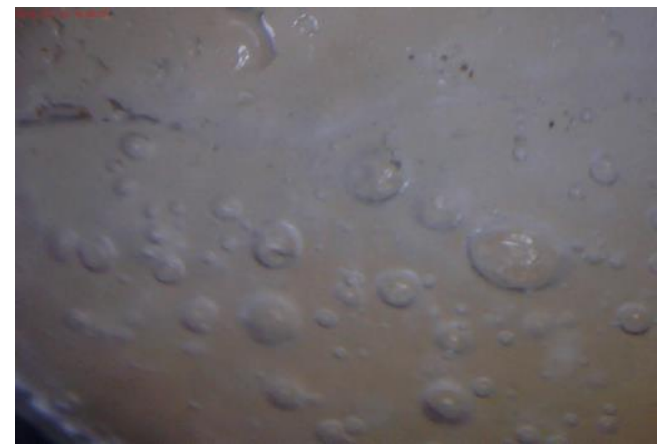

Fig. 4. Slow dissociation of the solid phase formed in $70 \%$ methanol solution $\left(P=0.6 \mathrm{MPa}, T=-32^{\circ} \mathrm{C}\right)$.
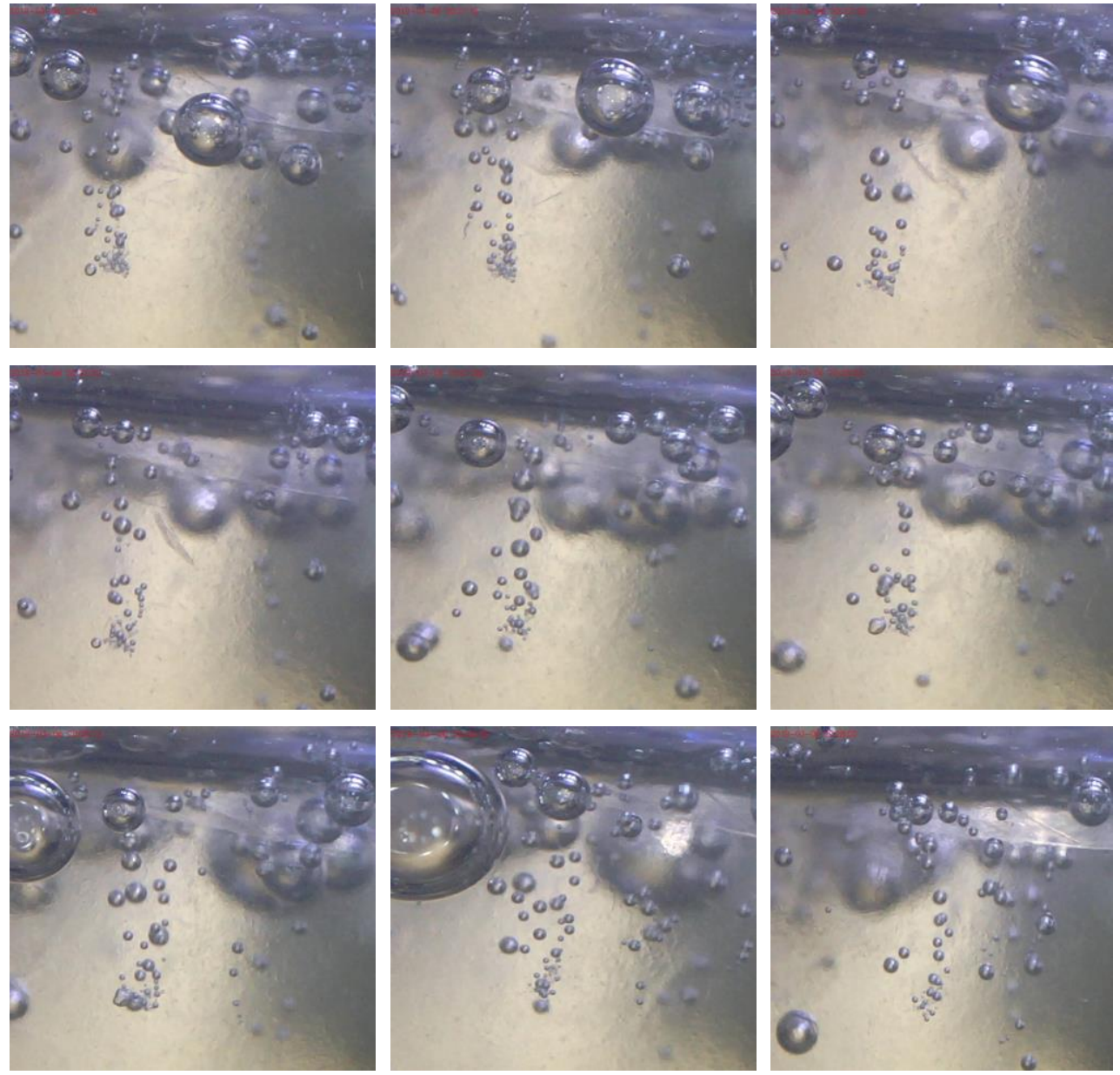

Fig. 5. Local zone with abnormal gas evolution.

Moreover, the amount of released gas in the composition of the bubbles flow clearly exceeds its possible content in the surrounding medium. The mechanism and source of these gas flows formation requires additional research with fewer system components and variable factors. 
2. When the concentration of methanol is $30 \%$ and ethanol is $40 \%$, to determine the hydrate formation parameters, it is advisable to apply the method consisting in fixing the moment of the light source reflection distortion on the interphase surface (Fig. 6).
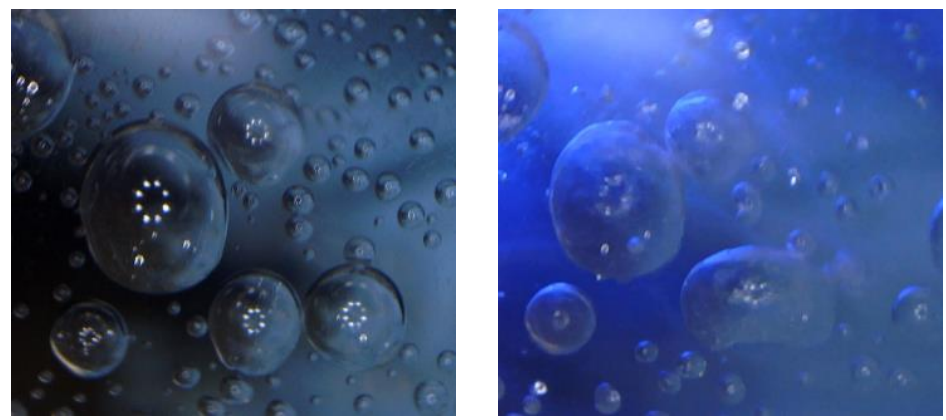

Fig. 6. Distortion of light source reflection on the interphase surface.

At higher concentrations, its application is complicated, because the solid phase formation in the solution is activated (visually fixed by the solution turbidity) (Fig. 7).
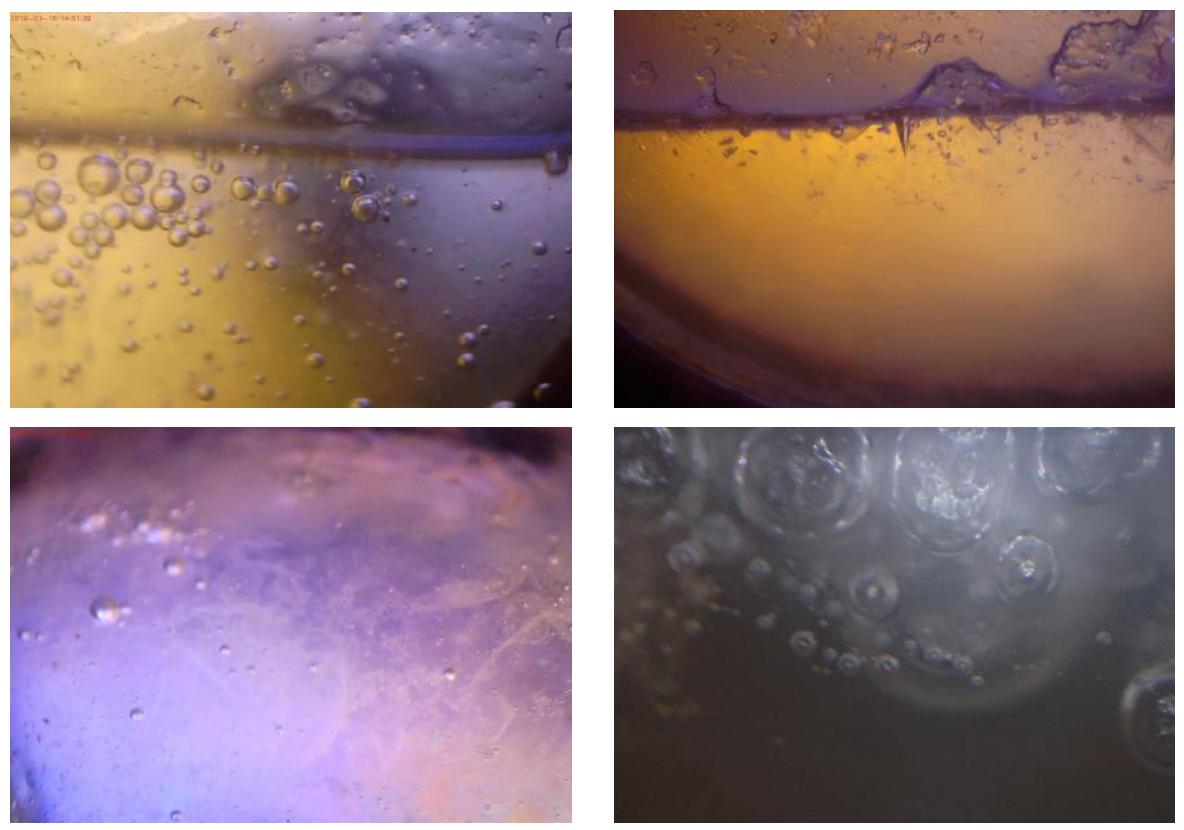

Fig. 7. Turbidity of methanol solution with a concentration of $60 \%$ during a solid phase formation.

3. The solid phase (a mixture of ice and gas hydrate) formed in highly concentrated solutions of methanol and ethanol is quite susceptible to mechanical impact. In addition, the solid phase particles for a long time do not show a tendency to agglomeration. The layer of liquid separates the particles, its presence is recorded by the reflection of the rays in Fig. 8.

These properties are developed to a greater extent in ethanol solution. 


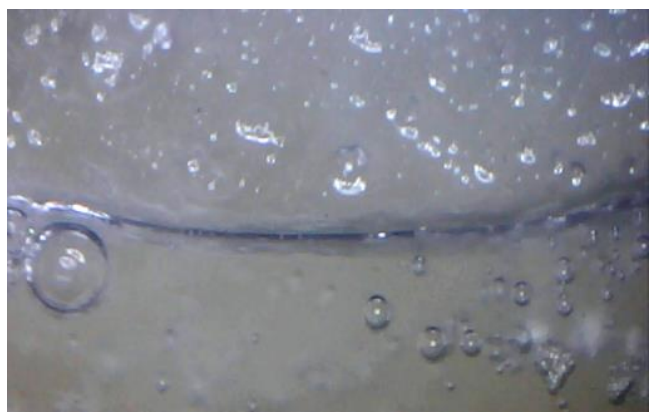

Fig. 8. Jelly-like structure of a solid phase mixed with concentrated ethanol solution.

\section{Conclusions}

Thus, in the system "inhibitor solution - gas hydrate - gas" in the process of gas hydrate recrystallization under the conditions close to equilibrium, microzones of supercooled water may occur which in the absence of gas molecules access will crystallize into ice. Therefore, after supercooling of the test sample (gas mixture and highly concentrated inhibitor solution) above the level of hydrate formation equilibrium, the formed solid phase will consist of gas hydrate and ice. Moreover, the gas hydrate does not contact directly with the inhibitor solution, but is in the ice in the form of inclusions. The result of such a solid phase structure formation is its increased stability in nonequilibrium conditions for a relatively long period of time.

The studied and described above mechanism of phase transformations and composing the components of the reservoir system in the presence of a concentrated inhibitor solution should be taken into account in the event of complications in the systems of gathering and treatment of oil and gas products. It should be taken into account that in the case of using at least thermodynamic inhibitors, the formed plugs will consist mainly of ice. This in turn should make adjustments in the event of its elimination.

In further research, it is advisable to expand the range of inhibitors used, to investigate the mechanism of the recrystallization process at the microlevel, as well as to clarify the process parameters.

The group of authors expresses their gratitude to the organizing committee of the conference "Gas Hydrate Technologies: Global Trends, Challenges and Horizons" and to the Department of Mining Engineering and Education in particular for the collaboration in research and for the development of the direction of gas hydrate technologies in Ukraine.

\section{References}

1. Kvenvolden, K.A. (1993). Gas hydrates - geological perspective and global change. Reviews of Geophysics, 31(2), 173-187. https://doi.org/10.1029/93rg00268

2. Bondarenko, V., Sai, K., Ganushevych, K., \& Ovchynnikov, M. (2015). The results of gas hydrates process research in porous media. New Developments in Mining Engineering 2015: Theoretical and Practical Solutions of Mineral Resources Mining, 123-127. https://doi.org/10.1201/b19901-23

3. Bondarenko, V., Kovalevs'ka, I., \& Ganushevych, K. (2014). Progressive technologies of coal, coalbed methane, and ores mining. London, United Kingdom: CRC Press, Taylor \& Francis Group. https://doi.org/10.1201/b17547

4. Pivnyak, G., Bondarenko, V., \& Kovalevska, I. (2015). New developments in mining engineering 2015. London, United Kingdom: CRC Press, Taylor \& Francis Group. https://doi.org/10.1201/b19901 
5. Sai, K., Malanchuk, Z., Petlovanyi, M., Saik, P., \& Lozynskyi, V. (2019). Research of Thermodynamic Conditions for Gas Hydrates Formation from Methane in the Coal Mines. Solid State Phenomena, (291), 155-172. https://doi.org/10.4028/www.scientific.net/SSP.291.155

6. Ovchynnikov, M., Ganushevych, K., \& Sai, K. (2013). Methodology of gas hydrates formation from gaseous mixtures of various compositions. Annual Scientific-Technical Colletion - Mining of Mineral Deposits, 203-205. https://doi.org/10.1201/b16354-37

7. Pedchenko, M., \& Pedchenko, L. (2016). Technological complex for production, transportation and storage of gas from the offshore gas and gas hydrates fields. Mining of Mineral Deposits, 10(3), 20-30. https://doi.org/10.15407/mining10.03.020

8. Nogami, T., Oya, N., Ishida, H., \& Matsumoto, H. (2008), Development of natural gas ocean transportation chain by means of natural gas hydrate (NGH). Procedeengs of the 6th International Conference on Gas Hydrates. Vancouver, Canada.

9. Gudmundsson, J., Graff, O., \& Kvaerner, A. (2003). Hydrate non-pipeline technology for transport of natural gas. In 22nd World Gas Conference (pp. 1-6). Tokyo, Japan: IGU.

10. Gudmundsson, J.-S., Parlaktuna, M., \& Khokhar, A.A. (1994). Storage of natural gas as frozen hydrate. SPE Production \& Facilities, 9(1), 69-73. https://doi.org/10.2118/24924-pa

11. Bondarenko, V., Svietkina, O., \& Sai, K. (2018). Effect of mechanoactivated chemical additives on the process of gas hydrate formation. Eastern-European Journal of Enterprise Technologies, 6(91), 17-26. https://doi.org/10.15587/1729-4061.2018.123885

12. Javanmardi, J., \& Moshfeghian, M. (2003). Energy consumption and economic evaluation of water desalination by hydrate phenomenon. Applied Thermal Engineering, 23(7), 845-857. https://doi.org/10.1016/s1359-4311(03)00023-1

13. Nagata, T., Tajima, H., Yamasaki, A., Kiyono, F., \& Abe, Y. (2009). An analysis of gas separation processes of HFC-134a from gaseous mixtures with nitrogen - Comparison of two types of gas separation methods, liquefaction and hydrate-based methods, in terms of the equilibrium recovery ratio. Separation and Purification Technology, 64(3), 351-356.

14. Bondarenko, V., Svietkina, O., Lysenko, R., \& Liu, B. (2020). Methane gas hydrates influence on sudden coal and gas outbursts during underground mining of coal deposits. E3S Web of Conferences, (201), 01002. https://doi.org/10.1051/e3sconf/202020101002

15. Sloan, E.D., Koh, C., \& Sum, A. K. (2009). Natural gas hydrates in flow assurance. Summer workshop (June 10-12). Colorado, United States: Colorado School of Mines.

16. Bondarenko V., Kovalevska I., Astafiev D., Malova O. (2018). Examination of phase transition of mine methane to gas hydrates and their sudden failure - Percy Bridgman's effect. Solid State Phenomena, (277), 137-146. https://doi.org/10.4028/www.scientific.net/SSP.277.137

17. Kinnari, K., Hundseid, J., Li, X., \& Askvik, K.M. (2015). Hydrate management in practice. Journal of Chemical \& Engineering Data, 60(2), 437-446. https://doi.org/10.1021/je500783u

18. Sloan, E., Koh, C., \& Sum, A. (2010). Natural gas hydrates in flow assurance. Oxford, United Kingdom: Elsevier, Gulf Professional Publishing, $224 \mathrm{p}$.

19. Maksymova, E., Ovchynnikov, M., Lysenko, R., \& Kostrytska, S. (2018). Physical and chemical methods of methane utilization in Ukrainian coal mines. Solid State Phenomena, (277), 147-156. https://doi.org/10.4028/www.scientific.net/SSP.277.147

20. Takeya, S., Ebinuma, T., Uchida, T., Nagao, J., \& Narita, H. (2002). Self-preservation effect and dissociation rates of $\mathrm{CH}_{4}$ hydrate. Journal of Crystal Growth, (237-239), 379-382. https://doi.org/10.1016/s0022-0248(01)01946-7

21. Stern, L.A., Circone, S., Kirby, S.H., \& Durham, W.B. (2003). Temperature, pressure, and compositional effects on anomalous or "self" preservation of gas hydrates. Canadian Journal of Physics, 81(1-2), 271-283. https://doi.org/10.1139/p03-018

22. Sloan, E.D. (1990). Clathrate hydrates of natural gases. New York, United States: Marcel Dekker.

23. Ohmura, R., Ogawa, M., Yasuoka, K., \& Mori, Y.H. (2003). Statistical study of clathrate-hydrate nucleation in a water/hydrochlorofluorocarbon system: search for the nature of the memory effect. The Journal of Physical Chemistry B, 107(22), 5289-5293. https://doi.org/10.1021/jp027094e 
24. Pedchenko, L., Nyemchenko, K., Pedchenko, N., \& Pedchenko, M. (2018). Use of alternative energy sources to improve the efficiency of natural gas hydrate technology for gas offshore deposits transportation. Mining of Mineral Deposits, 12(2), 122-131. 